\title{
Enantioselective N-Heterocyclic Carbene Catalyzed Mannich Reaction
}

\section{Key words}

Mannich reaction

NHC catalysis

enolates

B-amino acids

$1(10 \mathrm{~mol} \%)$
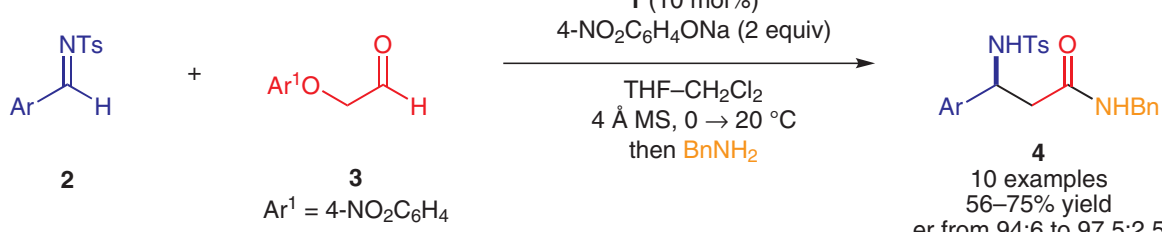

4

10 examples

$56-75 \%$ yield er from $94: 6$ to $97.5: 2.5$
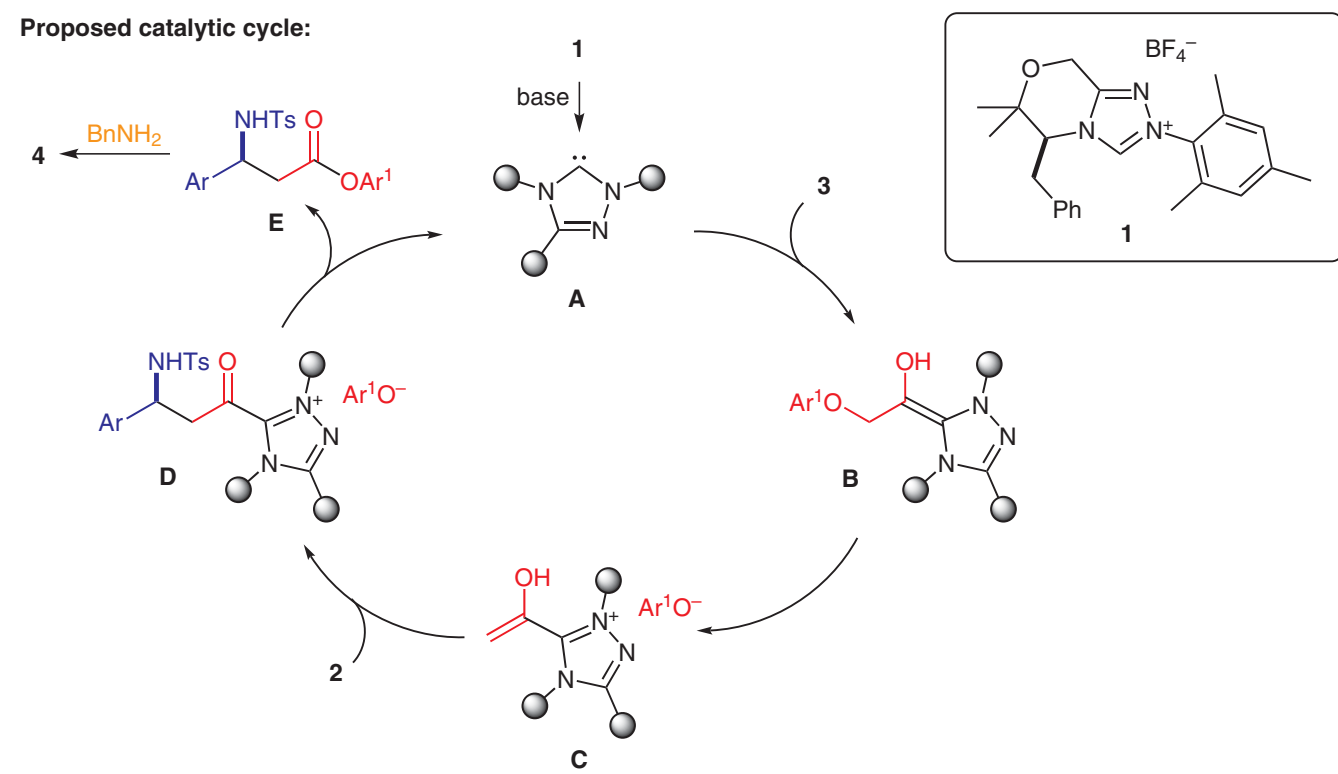

Significance: An enantioselective addition of $\alpha$-aryloxyacetaldehyde $\mathbf{3}$ to aromatic imines $\mathbf{2}$ was reported to proceed under $\mathrm{N}$-heterocyclic carbene catalysis. Initial products, amino esters E were transformed to the corresponding amides by treatment of the reaction mixture with benzylamine. With chiral precatalyst $\mathbf{1}, \beta$-amino amides $\mathbf{4}$ have been obtained in useful yields and high enantioselectivity. Other in situ transformations of E were also demonstrated affording $\beta$-amino alcohols, esters, carboxylic acids or peptides in a onepot reaction.
Comment: The catalytic generation of enolates is of a great importance due to their broad utility in organic synthesis. The Scheidt group previously reported that $\mathrm{N}$-heterocyclic carbenes catalyze the formation of enolates/enols through an elimination process of $\alpha$-aryloxyaldehydes (Org. Lett. $\mathbf{2 0 0 9}, \mathbf{1 1}, \mathbf{1 0 5}$ ). Here, they use this strategy to perform a Mannich reaction. Enolate/enol intermediate $\mathbf{C}$ is trapped by tosylimine to afford $\beta$-amino acyl azolium intermediate $\mathbf{D}$. Aryloxy anion liberated during enol formation step reacts with $\mathbf{D}$ to regenerate the catalyst and deliver the product E which serves as an activated intermediate for subsequent transformations.

SYNFACTS Contributors: Benjamin List, Ilija Čorić Dol: 10.1055/s-0029-1219136; Reg-No.: B15809SF 